Minireview

\title{
Purple bacterial light-harvesting complexes: from dreams to structures
}

\author{
Richard J. Cogdell ${ }^{1, *}$, Hideki Hashimoto ${ }^{2,3}$ \& Alastair T. Gardiner ${ }^{1}$ \\ ${ }^{1}$ Division of Biochemistry and Molecular Biology, Institute of Biomedical and Life Sciences, Davidson Building, \\ University of Glasgow, Glasgow G12 8QQ, UK; '2'Light and Control', PRESTO, Japan Science and \\ Technology Corporation (JST), Osaka, Japan; ${ }^{3}$ Department of Physics, Graduate School of Science, Osaka \\ City University, 3-3-138 Sugimoto, Sumiyoshku, Osaka 558-8585, Japan; *Author for correspondence (e-mail: \\ r.cogdell@bio.gla.ac.uk; fax:+44-141-3304620)
}

Received 7 April 2003; accepted in revised form 3 May 2003

Key words: bacteriochlorophyll, Brunisholz, Clayton, Cogdell, crystallography, Drews, Fleming, Ghosh, Gillbro, Hunter, Isaacs, light-harvesting complexes, Loach, Michel, Niederman, photosynthetic bacteria, Robert, Sauer, Scheer, Schulten, Sundstrom, Thornber, van Grondelle, Zuber

\begin{abstract}
This paper describes the main stages involved in the research efforts designed to try and understand the structure and function of purple bacterial antenna complexes. Wherever possible the work has been illustrated by pictures of the major people who carried it out.
\end{abstract}

Abbreviations: AFM - atomic force microscopy; BChl - bacteriochlorophyll; LH - light-harvesting; $R$-Rhodospirillum; Rb - Rhodobacter; RJC - Richard J. Cogdell; Rps - Rhodopseudomonas

\section{Introduction}

In 1975 when one of us, Richard Cogdell (RJC), returned to work in the UK after a period of postdoctoral research with Rod Clayton and Bill Parson in the US, very few people worked on, or were interested in, purple bacterial antenna complexes. Indeed, most of the research on light-harvesting ( $\mathrm{LH})$ in this bacterial system was being carried out by physical chemists, and the models that they were using did not involve any proteins! It is interesting, therefore, to go back and read the proceedings of the Ciba Foundation Symposium on Chlorophyll Organisation and Energy Transfer in Photosynthesis that was held in London in February 1978 (Wolstenholme and Fitzsimmons 1979), and organized by George Porter and Jim Barber. This symposium volume not only contains the papers but also records the discussions which followed each presentation. It is clear from these discussions that this meeting was one of the first occasions where the idea that purple bacterial LH complexes were really well defined pigmentprotein complexes began to get general acceptance. In fact it was already clear from several previous studies (Thornber 1970; Aagaard and Sistrom 1972; Clayton and Clayton 1972; Nieth and Drews 1973), of which one (Thornber 1970) is a particularly good example, that purple bacterial antenna complexes must be pigment-protein complexes rather than just pigment aggregates alone. In this short contribution we describe some of the major steps along the way from the days when purple bacterial antenna complexes were beginning to be characterized until now, when their detailed structure and function are very well understood. We illustrate our review with pictures of some of the main characters who have been involved in this work. We apologize to those people who are not included. This reflects our limited photographic collection rather than their relative contributions. 


\section{The story unfolds}

Figure 1 shows a photograph taken at the meeting banquet at the 1978 Ciba Foundation (now Novartis) Symposium mentioned above. It certainly reveals some interesting seventies hairstyles! Over the subsequent few years a great deal of work was carried out to characterize the purple bacterial antenna complexes, with particular emphasis on their pigment-binding apoproteins (Feick and Drews 1978; Broglie et al. 1979; Cogdell et al. 1980). It quickly became clear

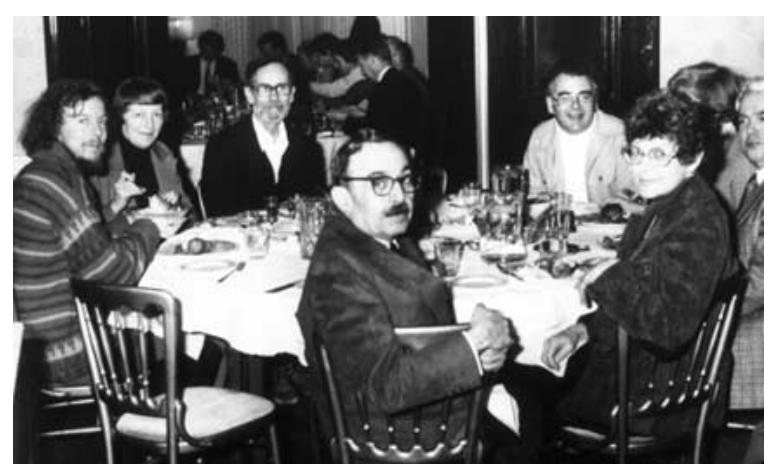

Figure 1. A photograph taken at the dinner of the Ciba Foundation symposium held in London in February 1978. Around the table from left, going clockwise are: Richard Cogdell, B.-J. Clayton, Rod Clayton, Phillip Thornber, Warren Butler (only half showing), Mrs Katz and Joe Katz.

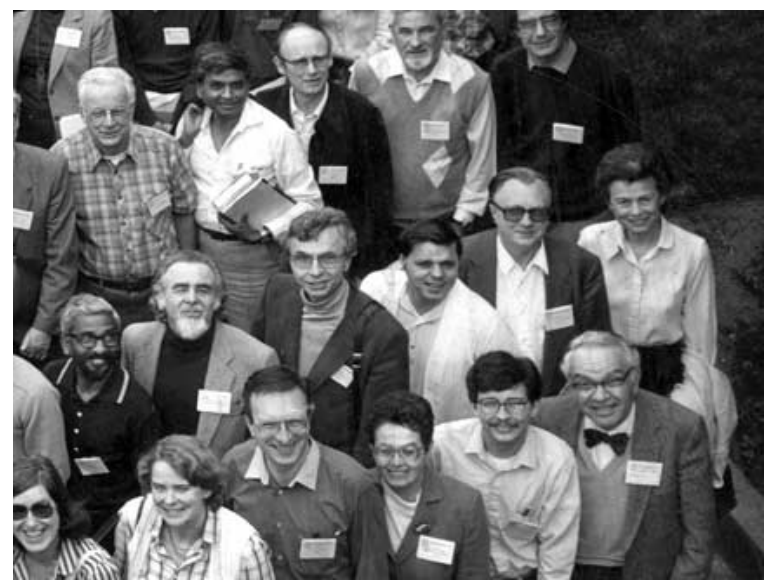

Figure 2. Part of a photograph taken from Bill Parson's Photosynthesis Gordon Conference in Santa Barbara in 1977. Top row from right: Hugo Scheer, Chris Sysbesma, Paul Mathis, Govindjee and Norman Good. Middle row from right: Beth Gantt, Herbert Zuber, unknown, Gerhart Drews, Maurice Windsor and Prasana Mohanty. Bottom row from right: Martin Kamen, Doug Youvan, Zippy Gromet-Elhanan, Gernot Renger, Meg Baltscheffsky and Jan Anderson. that these complexes are constructed on the same modular principle. Two low molecular weight apoproteins (called $\alpha$ and $\beta$ ), together with a fixed, small number of non-covalently bound bacteriochlorophyll (BChl) and carotenoid molecules, aggregated to form the intact, oligomeric native complexes (Cogdell and Thornber 1980). It was rapidly established that, in general, the purple bacterial antenna complexes could be divided

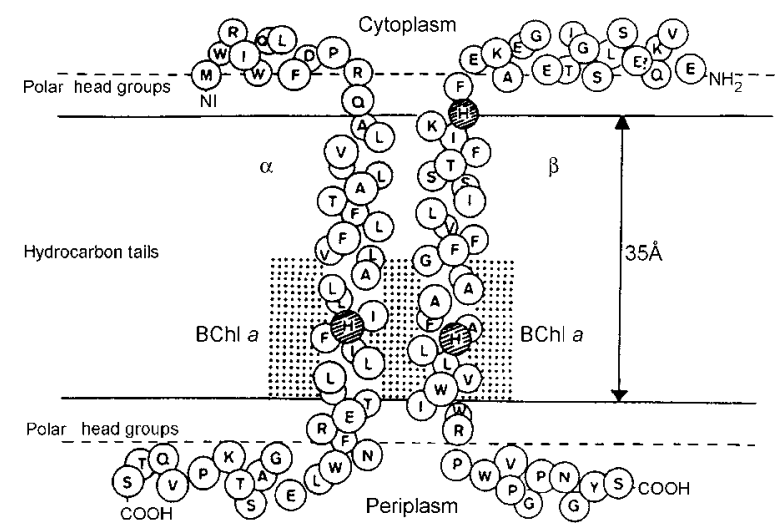

Figure 3. A model for the transmembrane arrangement of a bacterial LH1 antenna complex $\alpha / \beta$ subunit. Taken from Zuber (1987).

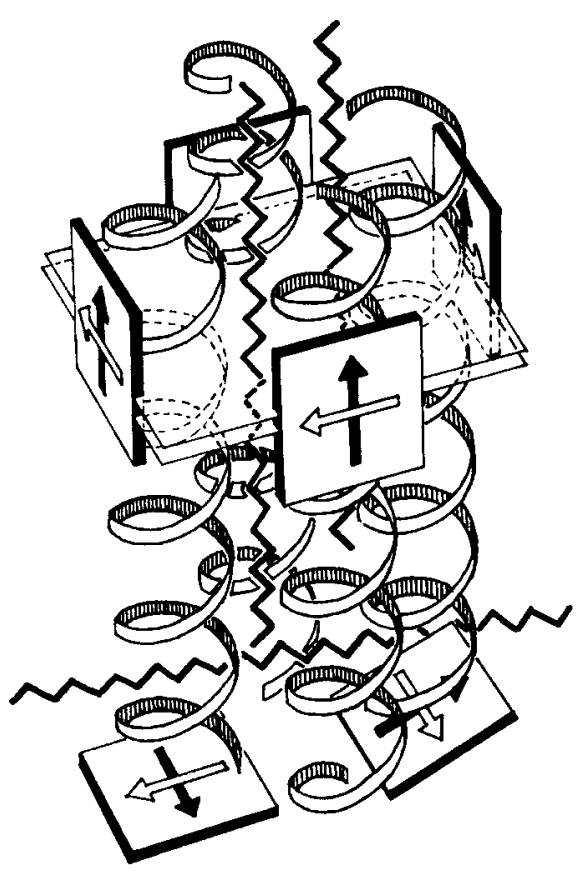

Figure 4. The Kramer model for an LH $2 \alpha / \beta$ subunit (Kramer et al. 1984). The squares represent the bacteriochlorin rings. The arrows represent the direction of the $Q_{x}$ (solid) and $Q_{y}$ (open) transition dipole moments. 




Figure 5. A composite picture, the main part of which was taken at the outing from the light-harvesting satellite meeting just before the 1995 Montpelier International Photosynthesis Conference. Left to right: Bruno Robert (inset), Neil Hunter, Rienk van Grondelle (inset), Richard Cogdell, Villy Sundström and Leonas Valkunas. Do not let anybody say science does not take you to beautiful places!

into two classes, which we now call LH1 and LH2 (Cogdell 1986). Some species only had LH1, for example, Rhodospirillum (R.) rubrum. In this case the size of their photosynthetic unit was always constant at about 30-40 BChls per reaction center (Aagaard and Sistrom 1972; Zuber 1986). Most species, however, such as Rhodobacter (Rb.) [known in those days as Rhodopseudomonas (Rps.)] sphaeroides had both LH1 and LH2. In this case, when cells are grown at low light-intensities the size of the photosynthetic unit could be enlarged by synthesis of increasing amounts of LH2 relative to LH1 (Zuber 1986).

Herbert Zuber (see Figure 2) and his group in Zurich embarked on a major protein-sequencing program to determine the primary structure of large numbers of these apoproteins. Since these apoproteins are so hydrophobic it was possible to extract them into a solvent of 1:1 chloroform:methanol, containing 5\% acetic acid. Also, because they are so small (generally about 50-60 amino acids in length) LH apoproteins can be readily purified by a combination of molecular sieve and ion exchange chromatography. Very often these proteins could then be completely sequenced by one run of repetitive Edman degradation. It is interesting to note that in this case direct protein sequencing is much faster than cloning and sequencing the corresponding genes. As a result of their efforts a large database of antenna apoprotein sequences was produced (for example, see Zuber and Brunisholz 1991).
Zuber's laboratory, and others, then carefully analyzed and compared these sequences to try to identify common structural features. In general, each apoprotein had a central hydrophobic core that was long enough to cross the photosynthetic membrane once as a transmembrane $\alpha$-helix. The $\mathrm{N}$ - and $\mathrm{C}$-termini were polar. Zuber's group pinpointed conserved histidine residues as likely ligands for the $\mathrm{Mg}^{2+}$ at the center of the BChl macrocycles, and correlated some aromatic, potential hydrogen bonding residues with the position of the long wavelength $\mathrm{BChl}$ absorption bands.

Figure 3 shows a topological model for the $\alpha$ and $\beta$ components of a purple bacterial LH1 antenna complex from that time (Zuber 1987). As the biochemical studies progressed there were several groups of physicists and chemists studying the energy transfer reactions in these antenna complexes, both in native photosynthetic membranes and in isolated, purified complexes. One paper (Kramer et al. 1984) was of particular significance because the available photophysical data were combined with the biochemical data to produce a model for the LH2 (Figure 4), which eventually proved to be remarkably good, especially in the prediction of the relative orientation of the BChl molecules. Interested readers should consult the review by van Grondelle (1985) to appreciate the status of energy transfer studies at that time. Through the intervening years, detailed understanding of the energy transfer reactions that take place in purple bac- 
terial antenna complexes has advanced hand in hand with advances in laser technology. As the laser pulses have shortened and the laser sources become more reliable, so faster energy transfer events have been resolved and our mechanistic insights have improved. Interested readers should consult a recent book by van Amerongen et al. (2000) that clearly illustrates this point.

The next major advance occurred when these models began to be elegantly tested using the new technique of site-directed mutagenesis. This interrogation of the structure/function relationships was begun by the group headed by Doug Youvan (see Figure 2) (Bylina et al. 1988), but the major driving force in this area has been Neil Hunter in Sheffield (Hunter 1995). The papers on the effects of changing the amino acid residues that are $\mathrm{H}$-bonded to the $\mathrm{B} 850$ BChls in the LH2 complex from $R b$. sphaeroides on the position of the $\mathrm{Q}_{\mathrm{y}}$ absorption are a beautiful example of the power of this approach (Fowler et al. 1992, 1994). Figure 5 shows pictures of Neil Hunter, Rienk van Grondelle (time-resolved spectroscopy) and Bruno Robert (resonance Raman spectroscopy), all of whom were involved in these studies.

In the 1980s, Paul Loach's group (Loach and Parkes-Loach 1995) developed an in vitro system to reconstitute the LH1 complex from its constituent components. This proved to be, and still is, a very useful way in which to begin to study the process of assembly of purple bacterial antenna complexes in vitro. However, there is little information about how these antenna complexes are assembled in vivo in spite of the excellent progress that was made in trying to understand the detailed molecular mechanisms involved in the harvesting of solar energy by purple bacterial

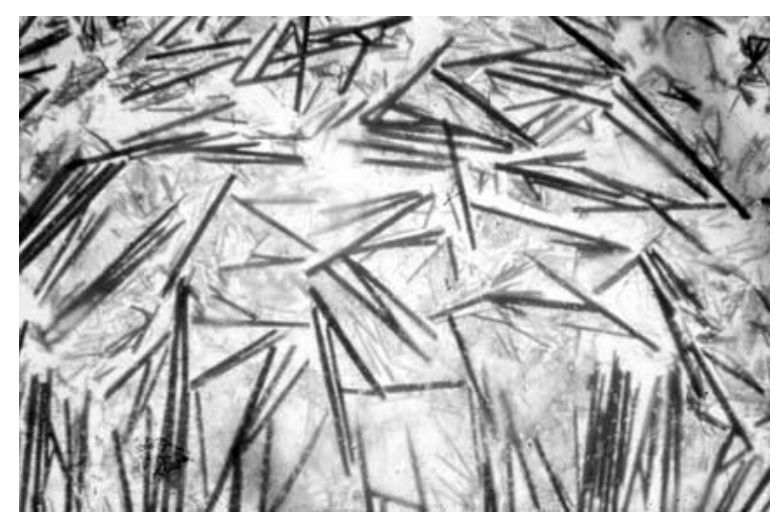

Figure 6. A picture of the first crystals of the LH2 complex from Rps. acidophila. A typical crystal in the photograph is about $100 \mu \mathrm{m}$ in length. antenna complexes, it was clear by the early 1980s that there was an urgent need to have a real structure of an antenna complex.

In 1983 RJC was lucky to be on a sabbatical in Munich in Hugo Scheer's laboratory. Across the city at Martinsried, Hartmut Michel had just crystallized the reaction center from Rps. viridis (Michel

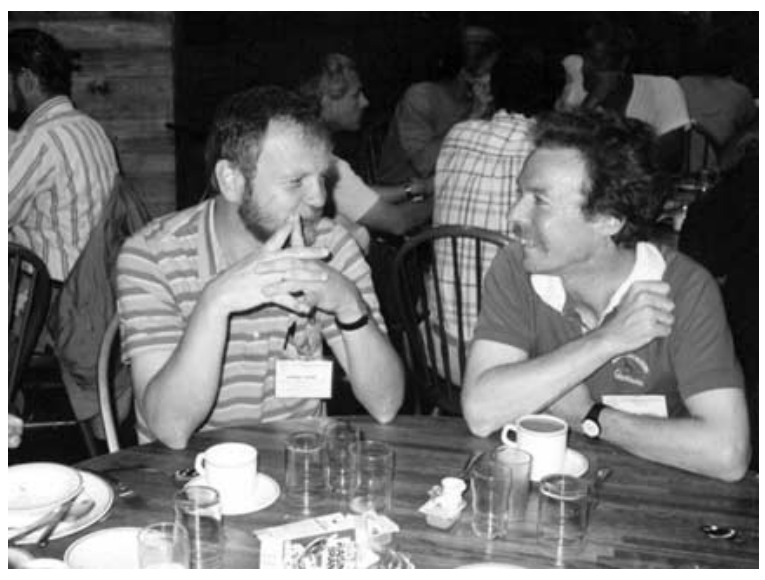

Figure 7. Breakfast at a photosynthesis Gordon Conference 1991. Hartmut Michel (left) and Richard Cogdell discussing 'progress' or rather non-progress in their attempts to get a high resolution structure of purple bacterial antenna complex.

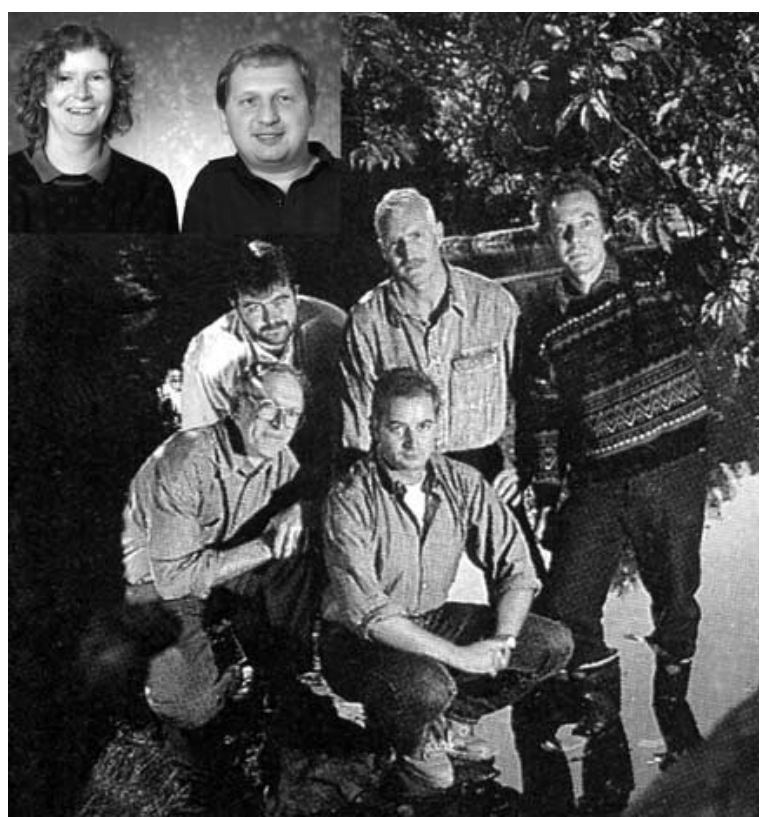

Figure 8. The successful Glasgow team that finally determined the LH2 structure. Inset (top left): Anna Lawless and Miroslav Papiz. Middle row, left to right: Steve Prince, Andy Freer and Richard Cogdell. Front row, left to right: Neil Isaacs and Gerry McDermott. 

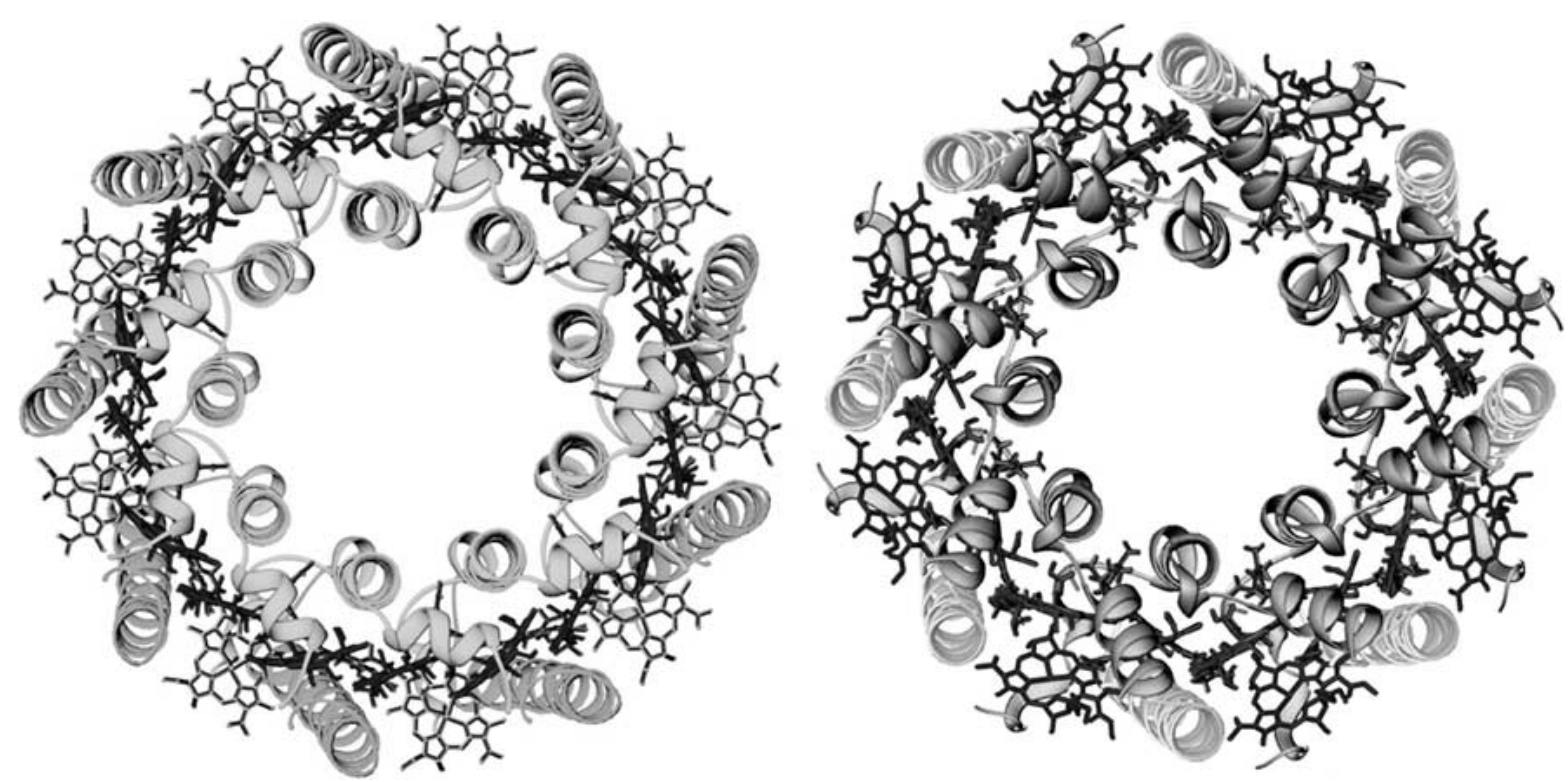

Figure 9. A comparison between the crystal structures of the nonamer LH2 from Rps. acidophila (left) and the octamer R. molischianum (right). The views shown are looking from the cytosol, down onto the top of the complexes in a direction normal to the plane of the membrane. For a color version of this figure, see color section in the front of the issue (Rps. acidophila (left): green, beta protein; cyan, alpha protein; magenta, B800 BChl; dark blue, B850 BChl; brown, carotenoid. R. molischianum (right): grey, beta protein; magenta, alpha protein; dark blue, B800 BChl; dark brown, B850 BChl; light brown, carotenoid).

1982), but had not yet solved its structure (Deisenhofer et al. 1985). Michel generously showed RJC how to go about trying to crystallize membrane proteins. Remarkably, in the first screening thin, needle-like crystals were obtained for the LH2 complex from Rps. acidophila strain 10,050 (Figure 6). Little did we realize how long it would take to go from these small, poorly ordered crystals to the determination of the crystal structure of this complex. Figure 7 shows RJC and Hartmut Michel at a 1991 Gordon Conference 'happily' discussing no progress! In the meantime Hartmut himself had got highly resolving crystals of the LH2 complex from $R$. molischianum, and throughout this period there was a 'friendly' competition to see who could solve the structure first.

Years of methodical work followed seeking good heavy atom derivatives, which are required to solve the phase problem before being able to use the $\mathrm{X}$ ray diffraction data to determine structure. It was clear from Zuber's many sequences that one structure would probably reveal all. In the background, Klaus Schulten was attempting to use computational methods to solve the structure of LH2 from R. molischianum (Hu et al. 1995). The race was finally won in Glasgow once Neil Isaacs arrived in 1989 and took up the Chair of Protein Crystallography, after which the structure was finally completed in the winter of 1994 (McDermott et al. 1995), following 10 years of work.

It was both very exciting and emotional when the electron density map of the Rps. acidophila LH2 first appeared on the computer screen. Figure 8 shows pictures of the people who were involved at the culmination of this project.

RJC then supplied Hartmut Michel and Klaus Schulten with the co-ordinates of the Rps. acidophila structure and, by a combination of molecular replacement and computational modelling, the structure of LH2 from $R$. molischianum was also determined (Koepke et al. 1996). Figure 9 shows the two structures, one with nine-fold symmetry (Rps. acidophila) and one with eight-fold symmetry (R. molischianum). With detailed structural information available, it was then possible to perform detailed quantum mechanical calculations to provide a theoretical basis for understanding both the spectroscopic properties and the energy transfer reactions of LH2. Klaus Schulten has been at the forefront of this approach (Hu et al. 1997) with notable contributions from other scientists in the field (Pullertis and Sundstrom 1996; Sauer et al. 1996; Scholes et al. 1999). 


\section{Prospects for the future}

Although for LH2 we now know in great detail about its structure and function, with most of its energy transfer reactions time-resolved down to a few tens of femtoseconds, virtually nothing is known concerning the assembly of LH2 in vivo. A substantial body of work has been carried out on the control of expression of genes encoding the proteins needed to produce antenna pigments and apoproteins (Young and Beatty 2003), but the assembly processes involved to produce the intact structure in the membrane remain elusive. Furthermore we have no idea what controls the oligomeric size of LH2. Are there, for example, more variants than the nonamer and octamer structures described above? Hopefully some of these basic questions will begin to be addressed in the near future.

Recently we have been able to determine the crystal structure of the LH1/RC 'core' complex from Rps. palustris at a resolution of $4.8 \AA$ (Roszak et al. 2003). Good progress therefore is being made in this area. However, there now is a need to go back to the intact photosynthetic membranes and begin to 'look' at the supra-molecular architecture of how LH2 and LH1/RC 'core' complexes are arranged relative to each other. In this regard a recent Atomic Force Microscopy (AFM) study from membranes of Rps. viridis, where these core complexes have been clearly visualized, is very exciting (Scheuring et al. 2003). Issues such as how much architectural variation is possible with retention of overall high efficiency utilization of solar energy can then start to be investigated. It is clear that research into light harvesting is moving into a very biological phase where key questions, pertaining to how the antenna system is constructed and regulated, are starting to be addressed.

\section{Acknowledgment}

This manuscript was edited by J. Thomas Beatty.

\section{References}

Aagaard J and Sistrom WR (1972) Control of synthesis of reaction centre bacteriochlorophyll in photosynthetic bacteria. Photochem Photobiol 15: 209-216

Broglie RM, Hunter CN, Delepelaire P, Niederman RA, Chua N-H and Clayton RK (1979) Isolation and characterisation of the pigment protein complexes of Rhodopseudomonas sphaeroides by lithium dodecylsulphate polyacrylamide gel electrophoresis. Proc Natl Acad Sci USA 77: 87-91

Bylina EJ, Robles SJ and Youvan DC (1988) Directed mutations affecting the putative bacteriochlorophyll-binding sites in the lightharvesting antenna of Rhodobacter capsulatus Israel J Chem 28 : 73-78

Clayton RK and Clayton BJ (1972) Relations between pigments and proteins in photosynthetic membranes of Rhodopseudomonas sphaeroides. Biochim Biophys Acta 283: 492-504

Cogdell RJ (1986) Light-harvesting complexes in the purple photosynthetic bacteria. In: Staehelin LA and Arntzen CJ (eds) Photosynthesis III Encyclopaedia of Plant Physiology, 19 (new series), pp 238-251. Springer-Verlag, Berlin

Cogdell RJ and Thornber JP (1980) Light-harvesting pigmentprotein complexes of purple photosynthetic bacteria. FEBS Lett 122: $1-8$

Cogdell RJ, Lindsay JG, MacDonald W and Reid GP (1980) A comparison of the constituent polypeptides of the B800-850 lightharvesting pigment-protein complex from Rhodopseudomonas sphaeroides. Biochim Biophys Acta 591: 312-320

Deisenhofer J, Epp O, Miki F, Huber R and Michel H (1985) Structure of the protein subunits of the photosynthetic reaction centre of Rhodopseudomonas viridis at $3 \AA$ resolution. Nature 318: 618-624

Feick R and Drews G (1978) Isolation and characterisation of light-harvesting bacteriochlorophyll protein complexes from Rhodopseudomonas capsulata. Biochim Biophys Acta 501: 499-513

Fowler GJS, Visschers RW, Grief GC, van Grondelle R and Hunter CN (1992) Genetically modified photosynthetic antenna complexes with blue shifted absorbance bands. Nature 355: 848-850

Fowler GJS, Sockalingum GD, Robert B and Hunter CN (1994) Blue shifts in bacteriochlorophyll absorbance correlate with changed hydrogen bonding patterns in light-harvesting 2 mutants of Rhodobacter sphaeroides alterations at $\alpha$-Tyr 44 and $\alpha$-Tyr 45. Biochem J 299: 695-700

Hu X, Xu D, Hamer K, Schulten K, Koepke J and Michel H (1995) Predicting the structure of the light-harvesting complex II of Rhodospirillum molischianum. Protein Sci 4: 1617-1682

Hu X, Ritz T, Damjonovic A and Schulten K (1997) Pigment organisation and transfer of electronic excitation in the photosynthetic unit of purple bacteria. J Phys Chem B 101: 3854-3871

Hunter CN (1995) Genetic manipulation of antenna complexes of purple bacteria. In: Blankenship RE, Madigan MT and Bauer CE (eds) Anoxygenic Photosynthetic Bacteria, pp 473-501. Kluwer Academic Publishers, Dordrecht, The Netherlands

Koepke J, Hu X, Müncke C, Schulten K and Michel H (1996) The crystal structure of the light-harvesting complex II (B800-850) for Rhodospirillum molischianum. Structure 4: 581-597

Kramer HJM, van Grondelle R, Hunter CN, Westerhuis WHJ and Amesz J (1984) Pigment-organisation of the B800-850 antenna complex of Rhodopseudomonas sphaeroides. Biochim Biophys Acta 765: 156-165

Loach PA and Parkes-Loach PS (1995) Structure-function relationships in core light-harvesting complexes (LH1) as determined by characterisation of the structural subunit and by reconstitution experiments. In: Blankenship RE, Madigan MT and Bauer CE (eds) Anoxygenic Photosynthetic Bacteria, pp 437-471. Kluwer Academic Publishers, Dordrecht, The Netherlands

McDermott G, Prince SM, Freer AA, Hawthornthwaite-Lawless AM, Papiz MZ, Cogdell RJ and Isaacs NW (1995) Crystal structure of an integral membrane light-harvesting complex from photosynthetic bacteria. Nature 374: 317-521 
Michel H (1982) Three dimensional crystals of a membrane protein complex: The photosynthetic reaction centre from Rhodopseudomonas viridis. J Mol Biol 158: 567-570

Nieth KF and Drews G (1973) Formation of reaction centres and light-harvesting bacteriochlorophyll-protein complexes in Rhodopseudomonas capsulata. Arch Microbiol 104: 77-85

Pullerits T and Sundström V (1996) Photosynthetic light-harvesting pigment-protein complexes. Toward understanding how and why. Acc Chem Res 29: 381-389

Roszak A, Howard TD, Southall J, Gardiner AT, Law CJ, Isaacs NW and Cogdell RJ (2003) Crystal structure of the RC-LH1 core complex from Rhodopseudomonas palustris. Science 302: 1969-1972

Sauer K, Cogdell RJ, Prince SM, Freer AA, Isaacs NW and Scheer H (1996) Structure based calculations of the optical spectra of the LH2 bacteriochlorophyll-protein complex for Rhodopseudomonas acidophila. Photochem Photobiol 64: 514-576

Scheuring S, Seguin J, Marco S, Levy D, Robert B and Rigaud J-L (2003) Nanodissection and high-resolution imaging of the Rhodospeudomonas viridis photosynthetic core complex in native membranes by AFM. Proc Natl Acad Sci USA 100: 1690-1693

Scholes GP, Gould IR, Cogdell RJ and Fleming GR (1999) Ab initio molecular orbital calculation of electronic couplings in the LH2 bacterial light-harvesting complex of Rhodopseudomonas acidophila. J Phys Chem B 103: 2543-2553
Thornber JP (1970) Photochemical reactions of purple bacteria as revealed by studies of three spectrally different carotenoid bacteriochlorophyll-protein complexes isolated from Chromatium strain D. Biochemistry 9: 2688-2698

van Amerongen H, van Grondelle R and Valkunas L (2000) Photosynthetic Excitons. World Scientific Publishers, Singapore

van Grondelle R (1985) Excitation energy transfer trapping and annihilation in photosynthetic systems. Biochim Biophys Acta 881: 147-195

Wolstenholme G and Fitzsimons DW (eds) (1979) Chlorophyll organisation and energy transfer in photosynthesis. Ciba Foundation Symposium 61 (new series). Excerpta Medica, Amsterdam

Young CS and JT Beatty (2003) Multi-level regulation of purple bacterial light-harvesting complexes. In: Parson W and Green BR (eds) Light-Harvesting Antennae in Photosynthesis. Kluwer Academic Publishers, Dordrecht, The Netherlands

Zuber H (1986) Comparative biochemistry of light-harvesting systems. In: Staehelin LA and Arntzen CJ (eds) Photosynthesis III Encyclopedia of Plant Physiology 19 (new series), pp 238-251. Springer-Verlag, Berlin

Zuber H (1987) The structure of light-harvesting pigment-protein complexes. In: Barber J (ed) The Light Reactions: Topics in Photosynthesis 8, pp 197-259. Elsevier Science, Amsterdam

Zuber H and Brunisholz RA (1991) Structure and function of antenna polypeptides and chlorophyll-protein complexes: principles and variability. In: Scheer $\mathrm{H}$ (ed) Chlorophylls, pp 627-703. CRC Press, Boca Raton, Florida 